\title{
Recycling and incineration, contradiction or coexistence?
}

Many times when discussing the implementation and optimisation of municipal solid waste (MSW) management in countries and regions all over the world, one faces arguments like 'the proposed technological and organisational solutions are too expensive', or 'incineration of waste kills recycling and is detrimental to the human health', and so on. These arguments reflect a blackand-white thinking and a partial view of the situation, and overlook technological advances during the last decades, as well as the globalisation of waste management and its changing role in becoming a resource-supplying sector.

It is true that the implementation of waste management systems must reflect cultural as well as socio-economic factors in order to be successful, and it is true that the implementation of modern waste management solutions can be very costly. But owing to our globalised economy, the technological challenges to provide an environmentally sound waste management system, given the composition and qualities of wastes to be handled, essentially are the same everywhere. Therefore, it is usually wise to consider, if not adopt, technological solutions that have proven to be successful in other parts of the world.

As waste management infrastructure and practices in a specific country evolve over time - a transition process that needs probably a few decades to transition from open dumping to modern state-of-the-art waste management - it is very important to look ahead and to consider possible future system optimisations when implementing today improved waste treatment systems. This is important in order to avoid stranded investments along the waste management evolution process. Bearing in mind possible future improvements when implementing waste management systems today enables planners to incorporate existing systems when future improvements are implemented. Therefore, stranded investments are avoided and the future investments are most probably minimised.

Let us look at the European situation regarding the coexistence of incineration and recycling as a show case for answering the question of whether these basic practices are in conflict or are able to gainfully coexist.

Waste incineration is the most widespread method of energy recovery of municipal solid (and for certain types of industrial) waste; incineration including heat recovery is applied in more than 450 waste-to-energy facilities across Europe and many more in the rest of the World. Recent data from Eurostat show that, despite decreasing amounts of waste generated, each person in the European Union (EU) on average produces $481 \mathrm{~kg}$ of municipal waste. In 2013 , that waste was managed by a variety of means:
Waste Management \& Research

2015, Vol. 33(8) 693-695

(c) The Author(s) 2015

Reprints and permissions:

sagepub.co.uk/journalsPermissions.nav DOI: $10.1177 / 0734242 \times 15593421$

wmr.sagepub.com

(S)AGE taking the over-all European average, 31\% was landfilled, 28\% recycled, $26 \%$ incinerated, and $15 \%$ composted. It is important to note that the share of recycled or composted municipal waste (in the EU) has steadily increased over the time period, from $18 \%$ in 1995 to $43 \%$ in 2013 (Eurostat, 2015).

In some European countries, like Switzerland, Sweden, the Netherlands, Norway, Denmark, and Estonia, close to half (or even more) of the municipal waste is incinerated. A substantial amount of energy recovered from that waste provides heat for district heating systems and/or steam for generation of electricity, acting as a locally available fuel and substituting for fossil fuels, which in most cases in Europe must be imported. But it is also noteworthy to learn that almost all of the previously mentioned countries have very high rates of recycling and composting (except Estonia, all five countries cited above exhibit less than $2 \%$ of municipal waste sent to landfills). At the other end of the scale are Eastern and South-eastern European countries, where most MSW is landfilled ( $99 \%$ or more in the case of some states of former Yugoslavia and Turkey).

Sometimes historical reasons determine the way MSW is treated. For example, while recovery of waste paper, cardboard, and glass became successful very quickly, the start of plastic waste recycling was not that easy. Recovery of plastic wastes was, and to a high extent still is, mainly realised through thermal processing, i.e. using plastics as a part of solid recovered fuel in cement kilns or steel furnaces. There have been, and there still are, reasons for that practice, such as inadequate source separation collection systems for plastic waste, lack of automated sorting equipment, and complex material composition - sometimes precluding high quality recycling. Currently, use of plastic wastes (made from fossil fuels) as a fuel itself is a relatively low cost option, in part owing to over-capacities for thermal treatment and high prices for fossil fuels. Some of these arguments can still be applied today also for other recyclables that are also combustible. These market conditions led to the situation where plastic wastes still are predominantly used as waste fuel in spite of the European Waste Framework Directive (European Parliament and Council, 2008) and the European Green Paper on Plastic Waste (European Commission, 2013) stipulating a higher priority to plastics recycling and even stating thermal utilisation to be appropriate only as an exemption if high-quality recycling is not feasible. The rationale for these regulations is that from a life-cycle analysis (LCA) perspective, plastics recycling does have significant advantages over thermal utilisation from a resource conservation point of view. This is owing to a high energy demand for plastics 
production and holds true even if energy recovery from thermal treatment is realised to a very high extent (Fricke et al., 2012).

The situation regarding plastic (and other recyclable and also combustible) wastes is changing now and collection systems are being optimised to enable capture of more recyclables from the waste stream. Highly sophisticated automated sorting technology has been developed during the last decade and has proven its applicability for plastic wastes as well as other materials. Furthermore, markets for recycled plastics have expanded and are driving an increase of recovery of this material. In addition, research regarding the use of waste plastics for the production of liquid fuels is on the way. In any way, recycling must imply the provision of secondary resources of the same quality and reliability as compared with that of primary resources. Owing to complex product compositions sometimes impeding efficient or effective recycling using available technology, it is not just the technological solutions that allow for recycling, but we need to make sure that products (including packaging) are designed for recycling, so that materials that may spoil the quality of secondary resources provided do not enter the recycling system in the first place.

On the other hand, energy intensive industries have invested in process technology and pollution control equipment allowing for environmentally sound energy recovery from waste during the last two decades. These industries still want to use locally available - often plastic rich - waste fuels. In view of recent developments in collection, processing and recycling of plastic waste energy recovery from plastic wastes becomes less attractive from an economical point of view as well. A part of the problem is that many already built and operating waste-to-energy plants rely on long-term contracts with the municipalities that provide them the waste-based fuel. Another issue is that modern waste-to-energy plants require large investments that cannot be paid off and earn profit in a short period of time; this means that it could take decades to phase out older technology and the reliance of combustibles in the waste stream. Municipalities are committed to supplying contracted quantities of waste through decades, which, critics of waste incineration claim, could suppress waste recycling rates and interfere with efforts to decrease waste generation at the source. On the other hand, based on a US study, some proponents of energy recovery argue that a large number of waste-to-energy plants facilitate the recycling of a number of materials by providing drop-off locations for recyclable materials, including electronic equipment, white goods, and other unwanted products (Governmental Advisory Associates Inc., 2014). In addition, many waste-to-energy plants employ metal recovery programmes onsite to remove ferrous and even non-ferrous metals from the ash.

The European Commission (EC) has withdrawn its 2014 proposal to set higher recycling targets (to recycle $70 \%$ of municipal waste and $80 \%$ of packaging waste by 2030 , and ban burying recyclable waste in landfills as of 2025). But the EC is continuing its efforts to transform Europe into 'a more competitive resourceefficient economy, addressing a range of economic sectors, including waste'. A new circular economy package is pending, to be published by the end of 2015 (European Commission, 2015). In all proposals, resource efficiency and recycling is given the highest priority, and it is very likely that the $\mathrm{EC}$ will insist on those very ambitious recycling targets. In addition to that, the EC will also focus on the product design of plastic products in order to further facilitate recycling. Today, only $24 \%$ of plastic waste in the EU is recycled, nearly $50 \%$ is landfilled, and the rest is incinerated.

This plastic waste management situation in the EU clearly shows that it is not about recycling or incineration, but all our efforts must be focused on plastic waste diversion from landfills. Although over-capacities in incineration are observed in European countries like Germany, in the Netherlands or Austria huge quantities of plastic waste still go to landfill in other European countries. During the last few years, some waste from the UK has been brought to the Netherlands and Germany to be incinerated; similar to that, Italian waste from the Napoli region, which faces an ongoing lack of appropriate waste treatment facilities, has been brought to Austria to be incinerated in a stateof-the-art incineration facility. Although these practices pose a contradiction to the European principle of vicinity, stating that waste should be taken care of where it is generated, it seems to be an appropriate solution to make use of existing incineration facilities and thereby diverting plastic waste from being landfilled. In sight of the fact that building new incinerators in those European regions that still landfill the plastic waste is very costly and takes a long time, we could make use of the incineration over-capacities in Central Europe by shipping the waste to these facilities. Knowing that transport accounts only for a minor portion of the over-all environmental impact in waste management (Ragoßnig et al. 2009), this could be an environmentally sound approach during the transition period while: (1) appropriate incineration capacities are being realised in less developed regions in Europe; and (2) incineration capacities in Central Europe are adjusting to lower waste quantities to be incinerated owing to higher recycling rates. This would allow for a planned decommissioning of older waste incineration facilities in Central Europe and thereby even allow for elevating the environmental standard of waste incineration; furthermore that approach would secure an economic reasonable spending of public budgets. But on the other hand, it would demand for a coordinated waste management planning on a European level.

All those aware of the need to decouple economic growth from resource use and pollution will agree to the necessity for more recycling, but there is also need for further discussion in that regard, because achieving any target diversion rates depends on the system boundaries to be applied for the calculation of the recycling rate as well as what will be defined as recycling, and how diversion is to be measured. To illustrate this, a previously shown recycling statistic does not include the fact that recycling of some materials is not completely effective, a situation that leaves substantial amounts of residues sent to landfills. But it should be noted that waste flow statistics also do not take into account that 
residues of the incineration process, $20 \%-25 \%$ of the waste that remains in the form of ash, are usually sent to landfills (in most cases after recovering coarse ferrous and non-ferrous metals), which currently is not accounted for under the landfilling rate. Furthermore, not all wastes sent to material recycling or waste-toenergy facilities are accepted owing to quality lapses; this material typically ends up in landfills (which is again not counted in waste flow statistics). And very often plastic is 'down-cycled' by reducing the quality of the material over time, not really recycled.

Regardless of whether the statistics and data from the EU and US studies showing that countries and communities with wasteto-energy facilities are more likely to have higher recycling rates than the national averages will be taken as relevant, we should strive to design systems where recycling and energy recovery complement each other and not to exclude otherwise beneficial processing. If properly organised, waste-to-energy could be a valuable part of an integrated approach to waste management that includes recycling as its core component. Waste-to-energy facilities are needed to take care of these wastes that cannot be recycled to provide a steady supply of high-quality secondary resources to global markets. Both methods (and any other) can be properly evaluated and integrated in the system by using the LCA methodology (or other sustainability accounting methods) that will scientifically and objectively consider all direct and indirect (including environmental) costs (like collecting and transporting recyclable materials) and benefits (e.g. more energy conserved by recycling than incinerating certain recyclable materials).

The articles published in this special issue of Waste Management \& Research were presented at two conferences on Sustainable Development of Energy, Water and Environment Systems (SDEWES), which were held in 2014 in Ohrid, Macedonia (SDEWES SEE) and on a cruise ship between Venice and Istanbul (SDEWES MED). These articles address many aspects of sustainable waste utilisation and treatment, but mainly in connection with the energetic utilisation of waste and waste biomass. The SDEWES Conference, sponsored by United Nations Educational, Scientific and Cultural Organisation (UNESCO), is a

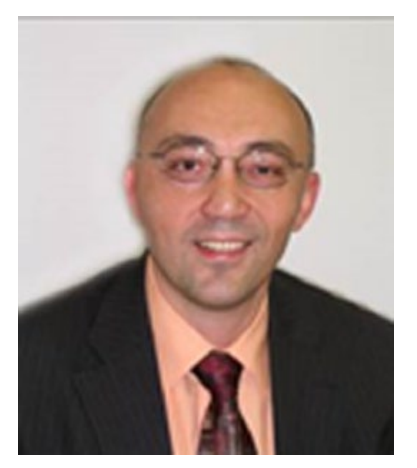

Daniel R Schneider

Department of Energy, Power

Engineering and Environment

Faculty of Mechanical Engineering

and Naval Architecture, University of

Zagreb, Croatia

Email: daniel.schneider@fssb.hr leading conference in the field of energy, sustainable development, and environment in the region. The next SDEWES Conference will be held on 27 September-3 October 2015, in Dubrovnik, Croatia. It will be dedicated to the improvement and dissemination of knowledge on methods, policies, and technologies for increasing the sustainability of development by de-coupling growth from natural resources and advancing towards a knowledge-based economy, taking into account its economic, environmental, and social pillars, as well as methods for assessing and measuring sustainability of development, regarding energy, transport, water, environment, and food production systems and their many combinations. More details regarding the conference can be found at: http://www.dubrovnik2015.sdewes.org/.

\section{References}

European Commission (2013) European strategy on plastic waste in the environment. Green Paper on Plastic Waste, Bruxelles.

European Commission (2014) Communication from the Commission to the European Parliament, the Council, the European Economic and Social Committee and the Committee of the Regions; Towards a circular economy: A zero waste programme for Europe.

European Commission (2015) Moving towards a circular economy, European Commission; Environment. Available at: http://ec.europa.eu/environment/circular-economy/index_en.htm (accessed 29 April 2015).

European Parliament and Council (2008) Waste Framework Directive, or Directive 2008/98/EC of the European Parliament and of the Council of 19 November 2008 on waste and repealing certain Directives.

Eurostat (2015) Eurostat News Release, Environment in the EU, Eurostat Press Office, 54/2015. Available at: http://ec.europa.eu/eurostat/ documents/2995521/6757479/8-26032015-AP-EN.pdf/a2982b869d56-401c-8443-ec5b08e543cc (accessed 26 March 2015).

Fricke K, Bahr T, Thiel T, et al. (2012) Recycling or energy recovery-resourceefficient action usually is climate sound action [Stoffliche oder energetische Verwertung - Ressourceneffizientes Handeln ist in der Regel klimagerechtes Handeln]. GCCS-Infoseminar, 4-5 June 2009. Braunschweig.

Governmental Advisory Associates Inc. (2014) Recycling and waste-toenergy: Are they compatible? Update 2014, the Energy Recovery Council, study by Governmental Advisory Associates. Available at: http://www. energyrecoverycouncil.org/waste-energy-recycling-compatible-a2975 (accessed 5 May 2015).

Ragoßnig A, Wartha C and Pomberger R (2009) Climate impact analysis of waste treatment scenarios - thermal treatment of commercial and pretreated waste versus landfilling in Austria. Waste Management \& Research 27: 914-921.

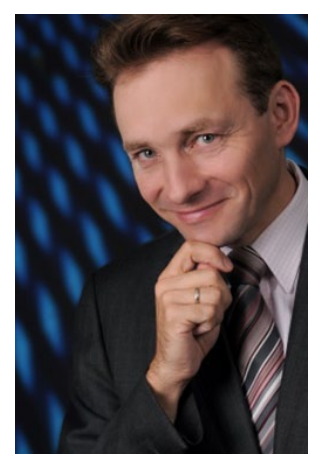

Arne M Ragossnig

UTC UmweltTechnik und

GeoConsulting ZT GmbH, Vienna,

Austria

Email: ragossnig@utc.co.at 